\title{
Presentación. Improvisación poética y performance. Aspectos antropológicos, literarios y musicales
}

Presentation. Poetic improvisation and performance. Anthropological, literary and musical aspects

María Pilar Panero García

Profesora Asociada, Departamento de Prehistoria, Arqueología, Antropología Social y CC. y TT. Historiográficas, Universidad de Valladolid (España)

mariapilar.panero@uva.es

\author{
IMPROVISACIÓN POÉTICA Y PERFORMANCE. ASPECTOS ANTROPOLÓGICOS, LITERARIOS Y \\ MUSICALES. \\ MONOGRÁFICO COORDINADO POR MARÍA PILAR PANERO GARCÍA (Universidad de Valladolid)
}

Patrocinado por la Cátedra de Estudios sobre la Tradición (Universidad de Valladolid)

\section{RESUMEN}

El presente monográfico indaga en la improvisación poética en la que confluyen la literatura y la música en el acontecer social. Este tópico se aborda desde varias perspectivas: la teórica, funcionalmente y desde la teoría de los géneros literarios; así como desde la didáctica. Asimismo, es analizado como fenómeno universal y diverso, que pervive profundamente arraigado e incardinado en la tradición. Finalmente, se enfoca desde la enriquecedora visión de los cultores que actualmente la practican explorando diversos caminos de creación poética y musical en una extensa variedad de contextos.

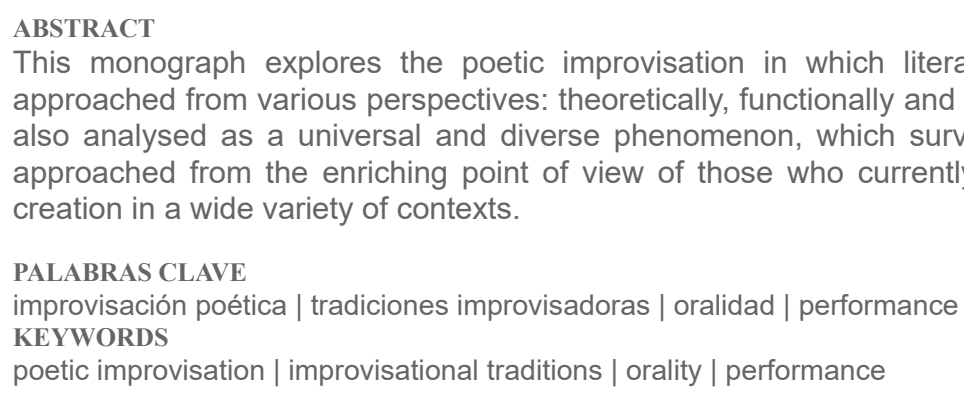
creation in a wide variety of contexts.

PALABRAS CLAVE

improvisación poética | tradiciones improvisadoras | oralidad | performance

KEYWORDS

poetic improvisation | improvisational traditions | orality | performance

This monograph explores the poetic improvisation in which literature and music converge in social events. This topic is approached from various perspectives: theoretically, functionally and from the theory of literary genres, as well as didactically. It is also analysed as a universal and diverse phenomenon, which survives deeply rooted and embedded in tradition. Finally, it is approached from the enriching point of view of those who currently practice it, exploring diverse paths of poetic and musical

\begin{abstract}
"Se pasaron años atravesando el interior de la Nueva España, que así se conocía estas tierras cuando empezaron su caminata. Se pasaban las horas tratando de vencer al otro con su picardía y la improvisación de sus rimas. Así caminaban de pueblo en pueblo envueltos en alegatos sobre cuál de los dos era el máximo y más diestro improvisador de versos. (...) Los alcaldes se quejaban porque en las plazas embelesaban a sus oyentes con su interminable vaivén de ideas" ("El viejo Vilmas y el negropoeta García", The Book of Archives and Other Stories from Mora Valley, New Mexico, Gabriel Meléndez).
\end{abstract}

\section{Improvisación poética y performance}

Toda la literatura oral se enuncia en un contexto performativo, idea sobre la que articula Paul Zumthor (1991: 33) su obra clásica Introducción a la poesía oral: "acción compleja por la que un mensaje poético es simultáneamente transmitido y percibido, aquí y ahora". Además, nos dice que se dan una serie de operaciones (producción, transmisión, recepción, conservación y, en general, repetición), siendo la improvisación propia en las de transmisión, conservación y repetición, mientras que la performance lo es de las de producción y recepción (Zumthor 1991: 33-34).

Podemos entender improvisación poética, oral, en un sentido laxo, como cualquier variante por accesoria que esta sea, o en el sentido más acotado cuando coinciden la producción y la transmisión de un texto. 
Entre la forma laxa y la más extrema, que es la repentización, hay una graduación de formas poéticas orales siempre asociadas y ejecutadas en contextos performativos y sujetas a los diversos contextos históricos y sociales.

José Manuel Pedrosa (2010: 33) nos previene del riesgo que entraña hablar de "literatura oral", de su ambigüedad y contradicción, de la imposibilidad de marcar lindes que permanezcan porque solo tiene sentido cuando se sitúa en "el trasvase continuo y multidireccional entre géneros, registros, gentes, lenguas, culturas, clases, cauces, soportes".

Los estudiosos de la improvisación resaltan la importancia que su transmisión y pervivencia tienen en algunos territorios en los cuales está asociada al fenómeno migratorio. Un ejemplo lo constituye el extraordinario caso canario por su vinculación privilegiada con Cuba (Trapero 2020: 308-311 y 343-346), tradición considerada "de ida y vuelta" (Díaz Pimienta 2003: 283). Otro es la gara que opera como anclaje de la memoria entre los emigrantes sardos en países como Suiza, Bélgica, Francia o Alemania y como "mecanismo cultural que sirve para evitar la asimilación" (Zizi y López 2013: 25) (1).

También el éxodo, asociado a una mejora estatus económico de los migrantes, puede provocar cambios de calado en su función. Así el trovo alpujarreño, antes la voz desgarrada y vehículo de la queja de los campesinos pobres, "difícilmente es reivindicativo, combativo o ideológico. Tras un comienzo revolucionario, termina siendo conservador, elemento de integración social, un 'sedante admitido', envuelto en la dialéctica del amor y el arte" (Checa 1996: 7). Los cambios históricos y sociales servirán de catalalizadores de muchos cambios estético-formales. El trovo antiguo de Las Alpujarras, antes canto vinculado a diversos trabajos campesinos, como ha cambiado de contexto y es cultivado por troveros y músicos no en las pedanías de la Contraviesa, Sierra Nevada y Sierra de Gádor, sino en las costas de Almería y Granada se ha separado del baile y otros elementos que sí estaban en la vieja tradición serrana (Díaz Pimienta 2003: 283 y ss.). Trasportado por los emigrantes a la zona minera de CartagenaLa Unión se fusiona con sus cantes "denominados fandangos de levante (tarantas y tarantos, mineras y cartagenera) y, por supuesto, con el 'trovo murciano"” (Checa 1996: 6).

Las formas poéticas que se memorizan y salmodian o declaman podemos definirlas de forma general en la poesía incorporada a performances y/o rituales. En ellos hay margen para la variación en formas establecidas (escritas) o que se combinan con otras de improviso (2). Si asumimos la improvisación de forma general, hallamos una verdadera panoplia de ejercicios poéticos que están en función de diversos contextos festivos, bien sean profanos o religiosos, y que no son exclusivos de ningún territorio.

Las formas laxas conviven con formas extremas de improvisación poética muy variadas en cuanto a la métrica y el acompañamiento musical y repartidas en todos los continentes (Díaz Pimienta 2014: 8-90). En España, habiéndose perdido en otras regiones (므), se dan el bertsolarismo vasco, la regueifa en Galicia, el trovo murciano, el trovo, las albáes y el cant de'stil en Valencia y Alicante, la corralada en Cataluña, el glosat en las Islas Baleares, el trovo alpujarreño en las provincias de Granada y Almería, el cante de los poetas del Genil en las provincias de Málaga, Córdoba y Granada, y el punto cubano, la meda y la polka majorera en las Islas Canarias.

En Portugal perviven distintos géneros como las cantigas ao desafio en Trás-os-Montes y el Alto Douro, las quadras en la comarca de Beja y el desafio o despique en las Islas Azores (Díaz Pimienta 2008 y 2014: 93-108, Trapero 2020: 287-306).

En México hay controversias o topadas en sones de fandangos y huapangos (huapango es un término polisémico que se utiliza para los sones en general). Allí "la tradición de la décima pervive en varias regiones, desde el norte en Tamaulipas hasta el sur en Yucatán, desde el occidente en Tierra Caliente hasta el Golfo de México en Veracruz; así como en los estados de Guanajuato, San Luis Potosí y Querétaro" (Rodríguez 2020: 7). Fernando Nava las divide según las denominaciones particulares:

\footnotetext{
“- 'Arribeña' (por su posición geográfica en relación con una región vecina, La Huasteca, que se sitúa "tierras abajo"); ocupa parte de los estados de San Luis Potosí, Guanajuato y Querétaro.

- 'Calentana' (propia a la 'Tierra caliente', en la depresión del río Tepalcatepec); se sitúa en una Porción del estado de Michoacán.

- 'Jarocha' (apelativo histórico para la población y la cultura de esa región); su núcleo se encuentra en la confluencia del sur del estado de Veracruz y la zona norte del estado de Oaxaca" (cit. en Rodríguez 2020: 7).
} 
Otros géneros poético-musicales americanos son la payada en Argentina, la trova paisa, la piquería y los decimeros en Colombia, el galerón y la décima zuliana en Venezuela, la payada uruguaya, la payá chilena, la décima y la trova en Puerto Rico, el canto de mejorana y los gallinos en Panamá, la décima esmeraldeña y el amorfino en Ecuador, el socabón y el amor fino en Perú, el chuín, la décima y la mediatuna en República Dominicana, y en portugués la pajada, los violeiros y otras formas en Brasil (Díaz Pimienta 2008 y 2014: 109-138).

Italia ha sido desde la Edad Media un territorio fértil en formas poéticas improvisadas y se mantiene con los cantastori y los stornellatori en la parte central (Toscana, Lazio y Los Abruzos), el sur y las islas (motetus en Sicilia y gara en Cerdeña) (Díaz Pimienta 2014: 90-93, Zizi y López 2020: 106-120).

Sin embargo, Zumthor (1991: 237-238) nos advierte de lo siguiente:

"la improvisación no es nunca total, el texto producido en el acto lo es en virtud de normas culturales, incluso de reglas preestablecidas. ¿Cuánto pesan esas normas en el improvisador? ¿Qué coacción quizá se derive de ellas? (...).

El improvisador posee el talento de juntar y de organizar rápidamente unos materiales en bruto, temáticos, estilísticos, musicales, a los que se mezclan los recuerdos de otras performances y con frecuencia fragmentos de escritura memorizados. O bien, si participa de una tradición mejor formalizada, construye, a la manera de los cantantes de blues, en el momento, unos textos siempre nuevos con unos elementos estándar".

Esta tesis se puede aplicar en algunas modalidades de improvisación poética extrema como el bertsolarismo en el cual se utiliza un repertorio de fórmulas, que el bertsolari implementa en el tiempo en que ejerce el oficio, que pueden encajar en diversos contenidos. Sin embargo, este trabajo previo considerando esquemas métricos establecidos, palabras como se utilizan en la escritura, etc. más lo que Joxerra Garzia (2008: 114) llama "circuito alternativo de rumiaje de la información social y personal" debe utilizarlo en una performance. La dificultad está en que desconoce el tema propuesto hasta que esta comienza. Es decir, "ha de ser capaz de improvisar sobre la marcha fórmulas contundentes y adecuadas" y "ha de ser un buen gestor de fórmulas que previamente haya podido elaborar" (Garzia 2008: 220). Esta mezcla de versos improvisados y "sabidos" se da en otras tradiciones poéticas como el son jorocho, con importante presencia de la improvisación que también es musical, en los estados mexicanos de Veracruz, Tabasco y Oxaca. Las modas y sonettos de la gara son partes escritas e improvisadas y escritas respectivamente.

Estudiando la literatura popular vemos como los textos transmitidos por tradición oral están trufados e influenciados por los cultos. El poeta popular incorpora conocimientos adquiridos en las letras impresas y que al copiar los manuscritos el copista, sobre todo si tiene ciertas dotes de compositor, no se priva de improvisar y dejar por escrito en el texto estrofas o versos de su propia cosecha, que a veces son poemas enteros. La división entre literatura popular oral o escrita, a veces es un nominalismo que sirve para acotar campos que permiten un estudio más acertado de los textos. Como sostiene Joaquín Díaz (2011), en una evolución que va del cuento al chiste, del cuento como popularización del mito y acercamiento de algunos relatos al pueblo, al chiste o la simple anécdota, que conserva aún los elementos de la narración clásica hecha para atraer o interesar. En todo ello se advierte el funcionamiento de la tradición en cuanto que consiste en el trinomio recibir-adaptar-entregar al grupo o al pueblo la tradición con el enriquecimiento lógico. Por eso es muy importante comprender el mecanismo que se opera en la transmisión de la cultura popular de tradición sea oral o escrita:

"Sería conveniente revisar, de vez en cuando, algunos de los conceptos sobre los que basamos teorías e hipótesis de trabajo. Nadie a estas alturas negaría, por ejemplo, que la cultura tradicional se transmite oralmente, de generación en generación; y, sin embargo, hasta sobre ese punto tan fundamental cabría hacer algunas reflexiones. (...) Habría, pues, que delimitar en el proceso o mecanismo tradicional, al menos tres aspectos: Recepción de material, decantamiento del mismo, y, finalmente, transmisión. Y en el primero de ellos tendríamos que clarificar qué parte corresponde a la entrega puramente oral y qué parte a papel escrito (romances, coplas, tonadillas, canciones de moda... aparecidas en pliegos, cancioneros y revistas ilustradas) cuya importancia se nos escapa precisamente por desconocer - el papel se suele destruir antes que la memoria - qué cantidad de textos llegaron a las manos de ese cantor o a las de su antepasado más próximo. Si en la actualidad pudiésemos reunir en colecciones todos los pliegos romancísticos aparecidos en diferentes imprentas españolas durante los siglos XIX y XX, habríamos avanzado un enorme trecho en nuestro camino sin necesidad de mover los pies" (Díaz 1983). 
Este monográfico refrenda la aseveración anterior pues la escritura de algunos poemas o fragmentos de poemas que nacieron y se comunicaron en un contexto repentista, porque la cultura es un acto comunicativo, ahora pueden ser escudriñados y almacenados en un periodo de tiempo amplio. La musa aprendió a escribir hace tiempo "cantora se trasmuta en escritora: ella que requería a los hombres que la escucharan los invita ahora a leer. Es justo asignarle ambos papeles" (Havelock 1986: 94).

También los podemos examinar a través de todos los registros audiovisuales que mediatizan la oralidad y la ofrecen en un tiempo diferido. En estos casos, además, se borra la misteriosa autoría colectiva tradicionalmente asignada al proceso de transmisión de la poesía oral, pues el versificador es un individuo reconocido como el de la "literatura" (Goody 1977: 48) o "literatura sabia" (Lévi-Strauss 1962: 301), si bien se sacrifica la inmediatez y el contacto con el receptor del mensaje oral. Este proceso, así como la "traición necesaria" al convertir "lo efímero en permanente", lo explican con detalle Daniela Zizi y Miguel López (2020: 183-191) en el caso de la gara sarda. A este respecto es muy interesante el trabajo de José Manuel Pedrosa en este monográfico. Él explica el registro en cancioneros por compiladores aficionados o por pulcros folkloristas, e incluso en hojas volantes impresas de baja calidad, de una lírica que escapa a cualquier taxonomía cerrada, o bien como improvisada o bien como tradicional.

El producir versos de repente (repentismo) puede ser un acto de creación improvisada, pero si después se pule, se transforma en una obra diferente. En cualquiera de los dos estadios, obra de improviso o pulida por el trabajo de escritor, son importantes la formación y las capacidades del autor, así como el contexto cultural en el que se producen los versos. De hecho, rimadores consagrados fueron famosos por ser capaces de crear composiciones al improviso en diversas justas poéticas.

Lope de Vega, al que mutatis mutandis podríamos considerar un influencer del siglo XVII, ya había utilizado el seudónimo de Burguillos en las justas poéticas celebradas en Madrid con ocasión de la beatificación y canonización de san Isidro en 1620 y 1622 respectivamente. Estas no fueron las únicas veces que Lope participó en este tipo de desafías a las que se refiere el también poeta y dramaturgo José de Valdivieso, que dice en la aprobación eclesiástica de Rimas humanas y divinas del licenciado Tomé de Burguillos (1634): "cuyo autor a no ser tan conocido en los certámenes públicos, donde se ha merecido los aplausos y los laureles" (Vega 2005: 107). Otros escritores asiduos de la corte como Francisco de Rojas Zorrilla, dramaturgo metido a poeta repentista, participaron en los certámenes que adornaban diversas fiestas (Julio 2004). En cualquier caso, estas disputas fueron unas manifestaciones muy populares desde finales del siglo XVI (Trapero 2020: 91-96).

Incluso estos poetas pueden ocasionalmente hacer una pequeña trampa al lector haciendo pasar por una forma repentizada unos versos que están en una comedia, género literario que primero se escribía y después lo representaban los actores tras su memorización, como este soneto de Lope de Vega (1925: 284), incluido en La niña de plata (1613):

"Un soneto me manda hacer Violante, que en mi vida me he visto en tal aprieto; catorce versos dicen que es soneto, burla burlando van los tres delante.

Yo pensé que no hallara consonante, y estoy a la mitad de otro cuarteto; mas si me veo en el primer terceto, no hay cosa en los cuartetos que me espante.

Por el primer terceto voy entrando, y parece que entré con pie derecho, pues fin con este verso le voy dando.

Ya estoy en el segundo, y aun sospecho que voy los trece versos acabando; contad si son catorce, y está hecho".

Todavía hoy, Gabriela Cabezón Cámara, en su novela Las aventuras de la China Iron (2017), se vale del poema Martín Fierro, ideal de payada del gaucho rioplatense (4), aunque sea fingida, y la reescribe en su estrofa predominante, el sexteto ajustado al esquema ABBCCB con rima consonante. El personaje que encarna al viejo coronel Hernández, en un juego paródico, roba los versos a Fierro equiparando al poeta 
emblemático que canonizó el género gauchesco con su personaje:

"Pero Hernández es ladrón

Me empezó a afanar los versos

Hizo libro'e mi canción.

La firmó con nombre de él,

Y le metió sus maldades:

¡Mirá que yo via cantar

'Hacete amigo del juez'!

El juez no es amigo de naides

Y obedece al coronel" (Cabezón 2019: 161).

Más allá del hábil juego literario en el cual Hernández, además de ladrón de versos, encarna irónicamente la utopía sarmentina que combatió en la vida real, la autora vuelve a reciclar la tradición versificadora auxiliada por las élites criollas del siglo XIX. Estas crearon discursos nacionales potentes, que han perdurado adaptándose más allá del folklore, en torno a la etnicidad del gaucho retratado en el gran poema épico nacional Martín Fierro. Sin embargo, Gabriela Cabezón, valiéndose de la payada (improvisación poética acompañada de guitarra) articula nuevos discursos nacionales en los que hay cabida para las otras identidades personales y sociales, que no necesariamente son las hegemónicas. Los indicadores identitarios del siglo XIX y gran parte del XX como producto cultural se reescriben en el XXI porque todavía tienen sentido.

El versificador moderno, al igual que Crisóstomo, que componía pensando en sus amigos los cabreros y otros aldeanos, también lo hace pensando en su auditorio. Un ejemplo de improvisación lo tenemos en el repentista Alexis Díaz Pimienta versificando ante un grupo de estudiantes de secundaria del instituto Vigán en Fuerteventura. Al repentizar utiliza vocabulario propio de las materias que se imparten en el currículo (mastoideo, trigonometría, fascista, hipotálamo, etc.) e incorpora Fortnite, nombre de un popular videojuego muy conocido por los jóvenes presentes, aunque solo sea de oídas (므): Y, en general, cualquier poeta que cree o reutilice versos de un repertorio pensando en que serán escuchados, "oralizados", pensará en los receptores.

\section{Presentación del monográfico}

Contamos en este número con el privilegio de que tres de sus autores son improvisadores y, además, son teóricos, profesores y divulgadores en distintas variedades de poesía repentizada. Yapci Bienes de la tradición versificadora canaria, Alexis Díaz-Pimienta del repentismo cubano y Enrique Fernando Nava López de la tradición del huapango arribeño nos ofrecen sus experiencias en un arte dinámico y diverso que resiste de forma vigorosa en la modernidad manteniendo la vocación comunitaria, léase también identitaria. Además, Enrique Fernando Nava en ocasiones ha sido invitado a tocar el segundo violín, por lo tanto, sin cantar, y en otras la guitarra huapanguera, ahora sí trovando; y Clara Macías canta y toca las jaranas en el son jarocho. Ellos nos apartan del tópico manido e impreciso de que la oralidad está ligada necesariamente a la creación anónima que se incorpora a eso que Tylor llamó cultura, aglutinando, además, versadores veteranos con una nueva generación.

La firma individual de muchos poetas orales se ha diluido en sus comunidades, pero muchos han sobresalido de la "misteriosa autoría colectiva" mucho antes de que mediante transcripciones escritas, grabaciones sonoras y registros audiovisuales se difundieran los versos que, en principio, nacían solo para un consumo efímero por un auditorio presente en el momento en que estos brotaban de los poetas. En buena medida, ahora acompañados de profesionales de la improvisación poética, hacemos un ejercicio para encapsular la oralidad con la escritura en Internet. Este proceso se ejecuta sin menoscabo de todos los niveles experienciales que viven aquellos que están presentes en una performance improvisadora cuando la poesía se hace voz. Recuperamos al respecto la reflexión de Walter J. Ong (1982: 169):

"Las culturas orales hoy en día estiman sus tradiciones orales y se atormentan por la pérdida de las mismas, pero nunca me he encontrado ni he oído de una cultura oral que no quisiera lograr lo más pronto posible el conocimiento de la escritura. (Desde luego, algunos individuos se resisten a la escritura, pero en su mayor parte se les pierde de vista pronto.) Sin embargo, la oralidad no es 
desdeñable. Puede producir creaciones fuera del alcance de los que conocen la escritura; la Odisea es un buen ejemplo. Asimismo, la oralidad nunca puede eliminarse por completo: al leer un texto se le 'oraliza'. Tanto la oralidad como el surgimiento de la escritura a partir de la oralidad son necesarias para la evolución de la conciencia”.

Este número de Gazeta de Antropología comienza con dos trabajos de corte teórico y general. El primero aborda, desde una perspectiva antropológica, todas las funciones y subfunciones sociales de la poesía improvisada desde un punto de vista holístico y un ámbito global. Los autores, Yacpi Bienes y Francisco Checa y Olmos, advierten de la densidad perceptible en su cartografía. La utilidad social de la poesía improvisada contribuye a la perpetuación de la cultura mediante la performance densa, la cual se amolda y se resignifica en la temporalidad diacrónica en función de las necesidades básicas o complejas de los grupos que la cultivan. La función relacional y la expresivo-comunicativa son funciones permanentes. Estas funciones conviven con otras que a su vez se establecen con otras circunstanciales que son propias de manifestaciones improvisadoras particulares. Sobrevivir proveyéndose de los bienes materiales, ganarse el pan, abre una puerta de infinitas posibilidades a la imaginación y la estética, en las que mora un universo simbólico y espiritual que propicia la acumulación de funciones. Esta multifuncionalidad refrenda la "osmosis constante entre lo imaginario y lo práctico" que señala Edgar Morin (1961) y de la que los autores nos ofrecen ejemplos ilustrativos.

El segundo trabajo general intenta paliar el olvido que ha sufrido la poesía improvisada desde la teoría literaria, concretamente desde las teorías de la comunicación. Esta se desarrolla necesariamente en un contexto pragmático y de la composición de los géneros literarios, puesto que está sometido a las reglas de composición y a los procesos creativos de sus autores. Sara Molpeceres Arnáiz plantea la posibilidad de observar la poesía repentizada como un subgénero del macrogénero lírico, considerando como central el contexto performativo y sus elementos extraliterarios. La autora se desliga de algunos de los tópicos generalizados con los que la crítica literaria, las escasas veces que lo ha hecho, ha tratado la repentización. Para ella, ni el innatismo ni las ideas simplistas y restrictivas acerca de lo popular pueden explicar un proceso creador y comunicativo colectivo muy complejo.

José Manuel Pedrosa inicia algunos de los estudios de caso que se abordan en el monográfico con un tópico literario antiguo, el de los nombres y cualidades de las damas, extendido y metamorfoseado en el ámbito hispánico hasta al menos los años finales del pasado siglo. El tópico, que también tiene su equivalente para los varones, puede ser de escarnio o de galante alabanza con dos categorías muy interesantes, la de los solteros y la de los donjuanes otoñales que repasan sus conquistas. En esta ocasión se centra en versiones de Argentina, Chile, Puerto Rico, México y Cuba. Parte de una evidencia que no siempre se considera, la improvisación y la tradición "se necesitan e implican", porque etnologíafilología o antropología-poética están obligadas a entenderse y compensarse. Opta por la existencia de una poesía híbrida más que improvisada o tradicional, que es simbiosis de ambas y en la que son oportunas otras disciplinas como la etnomusicología o la historia. El autor elige una pequeña antología extraída de importantes cancioneros campesinos u obreros. Los argentinos de Juan Alfonso Carrizo o del chileno Juan Uribe Echevarría son respectivamente una hermosa muestra en las que consigna los datos etnográficos conservados y establece un análisis tematológico comparatista. El tópico es dúctil y persistente y, como nos advierte el autor, da el salto del elenco emblemático y abstracto al histórico y real. Observamos idéntica misoginia, tanto en las postrimerías del s. XIX por los poetas populares chilenos, como en la transición al Renacimiento por el fundador de la lírica germanesca Rodrigo de Reinosa.

María Pilar Panero García se centra en algunas de las tradiciones versificadoras populares y la performance en la que se producen en Castilla y León, especialmente en la zona occidental. Las primeras no se entienden sin la segunda y, aunque la versificación se da en muchos contextos, la autora se ha centrado en antiguos ritos de paso de los que destacan algunas composiciones carnavalescas de performance global. Recoge algunas que han muerto, pero se detiene en algunas que están vivas a pesar de los procesos globalizadores y homogeneizadores impuestos a las sociedades rurales en la segunda mitad del siglo XX. En muchas de estas celebraciones la catarsis a través de la palabra poética es central en la ritualidad. Se destaca la importancia del versificador profesional y local capaz de ofrecer a la comunidad lo que es "noticia" en el año, así como la permanencia de muchas poesías en cancioneros o colecciones, aun cuando el contexto en el que se reproducían no existe.

Los siguientes trabajos se refieren a dos de las formas musicales del rico folklore mexicano, el huapango arribeño y el son jarocho. El primero está centrado en la controversia poética y el segundo en aspectos 
musicales y rituales, si bien ambos reflejan los diversos niveles estéticos y funcionales en estos dos sones que se componen de lírica, acompañamiento musical y danza.

Agustín Rodríguez Hernández analiza la parte improvisada del huapango arribeño, que se da principalmente en los estados de Guanajuato y Querétaro y también en algunos lugares de San Luis Potosí. El autor elige la parte del decimal en la que se improvisan la glosa y las décimas en una topada, controversia entre dos poetas. Estos son conocidos siendo uno un poeta consolidado, don Agapito Briones, y otro prácticamente novel, don Cándido Martínez. Más allá del reto poético ambos trovadores demuestran en su puesta en escena, la fiesta dura toda una noche, el conocimiento de la tradición, el sentir de la comunidad, que es auditorio, y sus anhelos y preocupaciones cotidianas. Esta información se teatraliza en un duelo entre caballeros en el que hay lugar para las pullas y la cortesía exquisita, entre ellos y hacia todos, pero en el que la comunidad socializa a través del baile, la música y la poesía.

Clara Macías Sánchez y Enrique Fernando Nava López reflexionan sobre los procesos actuales de revitalización de ritualidades en contextos festivos. El motivo elegido es una variedad poético-musical acompañada de baile, el son jorocho, entendido este como "son jarocho tradicional" a pesar de los procesos migratorios, desconfesionalizadores, democratizadores y turísticos acometidos desde el último tercio del siglo XX que han cambiado la cultura popular de origen campesino. Los autores se centran concretamente de una variedad que mantiene un uso devocional, los acarreos y velorios de imágenes sagradas, en un contexto lúdico-festivo e intergeneracional. Nos desgranan las formas de sociabilidad modelada de forma diacrónica y la resignificación de estas variedades y su diversidad formal y funcional. Denominan "santos visitantes" a las imágenes que son solicitadas en otro pueblo y se trasladan acompañadas de jaraneros, violineros y guitarreros donde el acarreo es el desplazamiento; mientras que el velorio es la segunda fase en la que se vela la imagen con acompañamiento musical. La celebración de los jarochos reconstruye el imaginario colectivo de la comunidad favoreciendo redes solidarias y fortaleciendo los sentimientos identitarios también de grupos minoritarios.

Rosario Perricone pone el foco en algunas canciones carcelarias registradas por Giuseppe Pitrè. Estas dieron pie a una polémica científica con Cesare Lombroso. Parte de la monumental obra de Pitrè debe ser analizarla en su contexto histórico, única porque es un autor singular, pero que trabajó partiendo de la cultura italiana y europea de su tiempo. Los dos volúmenes de canciones populares sicilianas de Pitrè, que incluyen más de mil canciones en la edición de 1870-1871 y están anotados y precedidos por su estudio crítico, serán el germen de la Biblioteca de Tradiciones Sicilianas. Lombroso hace unas observaciones restrictivas y simplistas de las canciones carcelarias adscribiéndolas, sobre todo, a Sicilia y Cerdeña, que identifica con una mayor incidencia del crimen. Pitrè, que comienza a trabajar desde una perspectiva romántica-literaria que se convierte en científico-positivista, reprocha a Lombroso varias cuestiones: la identificación de la oralidad exclusivamente con la poesía; y sondear la acción criminal en base a una oralidad que no es exclusiva de los territorios insulares italianos, sino de todo el país. En la última parte del ensayo el autor traslada esta polémica antigua al hoy reflexionando sobre como la tradición se convierte en historia contemporánea.

Cierra el número un ilustrativo trabajo de carácter introspectivo que hace un repentista reconocido y admirado como Alexis Díaz Pimienta. El autor -que cuenta con una importante obra de creación literaria que incluye poesía, novela, cuento para adultos y para niños según el modelo prestigiado de literatura, el escrito por un emisor cualificado para un receptor también cualificado- ha elaborado un método que desmonta los tópicos que atribuyen a la lírica popular, la privación de técnica (Díaz Pimienta 2017), que, sí se atribuye a la poesía y, en general, a toda la literatura que nace escrita. Ahora elige el autorretrato creador frente al retrato académico, nos muestra la génesis creadora de un poeta repentista con una tradición familiar y una praxis dilatada y fecunda en el oficio. El motivo que explora y que ahora nos ofrece es un anticipo de un trabajo más amplio que está preparando sobre los mitos y ritos de la inspiración poética. Ahora nos brinda dos décimas improvisadas en clave onírica en las que convida al lector a seguir su proceso mental y creativo. El repentista en sueños nos procura un "Ir y venir, seguir y guiar, dar y tener, entrar y salir de fase / Amar la trama más que el desenlace", como canta Jorge Drexler, en un juego didáctico. La propensión a la imaginación y el bagaje del poeta se integran en una técnica bien definida y estructurada para gestar y alumbrar la décima.

Agradecemos a todos los autores que han hecho posible este monográfico; a la Cátedra de Estudios sobre la Tradición (Universidad de Valladolid) su implicación en él, especialmente a su director, el profesor José Luis Alonso Ponga; al equipo de la revista Gazeta de Antropología la amabilidad, diligencia 
y asertividad en todo el proceso editorial, con una mención personal a Francisco Checa y Olmos y a José Luis Solana Ruiz que han guiado nuestros pasos; y a los revisores de los trabajos la mirada especialista y la crítica constructiva con la que han cumplido con su tarea. Confiamos en haber aportado algo de claridad en el complejo, amplio y fértil espectro de la improvisación poética, agente privilegiado para revelar las muchas facetas de la conciencia humana.

\section{Notas}

1. Véase la información que aportan Daniela Zizi y Miguel López (2013: 20-25) sobre los circoli sardi all'estero que se organizaban para emigrantes repartidos en Europa y lugares remotos, pero también para emigrantes sardos repartidos en las regiones del norte de Italia como Lombardía, Piamonte, Véneto o Emilia Romaña.

2. Versificar de improviso se puede hacer en diferentes formas métricas, por ejemplo, en quintillas, como esta archiconocida que la tradición atribuye a José Zorrilla: "Me levanto de esta silla / sólo para demostrar / que el hacer una quintilla / es la cosa más sencilla / que se pueda imaginar". - Este es un poeta muy prolijo al que persiguió la fama de no dedicar demasiado tiempo a seleccionar sus rimas y seguir unos estereotipos pautados, por lo que componía ripios muy repetitivos. Según Bienvenido Morros, la sonoridad y la buena voz para recitarlos fueron claves en su éxito, mucho más que el mensaje (Zorrilla 2017: 139-140). Es decir, que escribía prácticamente según nacían sus versos.

3. Por ejemplo, por la "americanización forzada" que han tenido los hispanos nuevoamericanos en las dos últimas generaciones. Sin embargo, hubo una vigorosa tradición versificadoras de puetas que se enfrentaban en alardes improvisados o de memoria que sobrevivieron a la independencia española (1821) y más allá de la anexión a Estados Unidos (1912), momento en el que todavía se aspira a mantener la identidad cultural hispana. Hoy se conservan parte de la memoria de esa costumbre de "echar versos": "décimas a lo divino, filosóficas, morales, de amor, décimas con nombre de mujer, de hombre o de lugares, humorísticas, satíricas y de sucesos varios” (Lozano 2008: 78).

4. José Hernández en el Martín Fierro refleja la versatilidad del gaucho también con la payada, Fierro es ante todo un cantor de la desdicha del gaucho. El "cantar de contrapunto" entre Martín Fierro con El Moreno, en principio vengador de la muerte de su hermano a manos de Fierro, redondea ese destino. El desafío entre ambos (Hernández 1872: 322-341) es un ejemplo de las disputas poéticas entre gauchos y negros que se representaban performativamente en la payada.

5. Disponible en https://www.youtube.com/watch?v=J314meDVBsg.

\section{Bibliografía}

Cabezón Cámara, Gabriela

2019 Las aventuras de la China Iron. Barcelona, Penguin Randon House.

Checa, Francisco

1996 "El trovo alpujarreño. De lo lírico a lo satírico", Gazeta de Antropología, n ${ }^{\circ}$, artículo 07. http://hdl.handle.net/10481/13588

Díaz, Joaquín

1983 "Editorial", Revista de Folklore (Urueña, Valladolid), nº 25.

2011 "Espacios creativos en el cuento tradicional. Fórmulas creativas en la narrativa popular".

https://funjdiaz.net/joaquin-diaz-articulos-ficha.php?id=20401

Díaz Pimienta, Alexis

2003 "La poesía oral improvisada: un ritual desconocido", en Ritualidades latinoamericanas: un acercamiento interdisciplinario/Uma aproximaçã 0 interdisciplinar. Madrid, Editorial Iberoamericana/Vervuert: 281-304.

https://elibro-net.ponton.uva.es/es/ereader/uva/36790?page=7.

2008 "La décima como estrofa para la improvisación", en La voz y la improvisación. Imaginación y 
recursos en la tradición Hispánica. Urueña (Valladolid), Fundación Joaquín Díaz: 106-127.

2014 Teoría de la Improvisación Poética. Almería, Scripta Manent Ediciones.

2017 Método Pimienta para la enseñanza de la improvisación poética. Almería, Scripta Manent Ediciones.

Garzia, Joxerra

2008 "El bertsolarismo. Realidad, investigación y futuro de la improvisación oral vasca", en La voz y la improvisación. Imaginación y recursos en la tradición hispánica. Urueña (Valladolid), Fundación Joaquín Díaz: 210-227.

Goody, Jack

1977 La domesticación del pensamiento salvaje. Madrid, Akal, 2008.

Havelock, Eric A.

1986 La musa aprende a escribir. Reflexiones sobre oralidad y escritura desde la Antigüedad hasta el presente. Barcelona. Paidós, 1996.

Hernández, José

1872 Martín Fierro. Madrid, Cátedra, 1997. Edición de Luis Sainz de Medrano.

Julio, María Teresa

2004 "Francisco de Rojas Zorrilla: Un dramaturgo metido a poeta. Las fiestas de 1637", en María Luisa Lobato y Francisco Domínguez Matito (ed.), Memoria de la palabra. Actas del VI Congreso de la Asociación Internacional Siglo de Oro, t. II. Madrid, Iberoamericana-Vervuert: 1121-1132.

Lévi-Strauss, Claude

1962 El pensamiento salvaje. México D. F., Fondo de Cultura Económica, 1997.

Lozano, Tomás

2008 "Trovos y cañuteros: ingenio y humor en Nuevo México", en La voz y el ingenio. El humor, el chiste, la ironía, el gesto intencionado. Urueña (Valladolid), Fundación Joaquín Díaz: 76-93.

Morin, Edgar

1961 "Los complejos imaginarios", Gazeta de Antropología, no 35 (2), 2019, artículo 04. http://hdl.handle.net/10481/62151

Ong, Walter J.

1982 Oralidad y escritura. Tecnologías de la palabra. México D. F., Fondo de Cultura Económica, 2006.

Pedrosa, José Manuel

2010 “¿Literatura oral? ¿Tradicional? ¿Popular? ¿Mitología popular?”, en AA. VV., Literatura popular. Definición y propuesta de bibliografía básica. Urueña (Valladolid), Fundación Joaquín Díaz: 31-38. https://funjdiaz.net/imagenes/actas/2010literatura.pdf

Rodríguez Hernández, Agustín

2020 "La topada de poetas: Estructura, características y tradicionalidad en una fiesta ejidal", Boletín de Literatura Oral (Jaén), anejo 4.

https://doi.org/10.17561/blo.vanejo4.5610

Trapero, Maximiano

2020 Un arte verbal muy vivo y vivaz. Estudios sobre la décima y la improvisación poética. Madrid, CIOFF España.

Vega, Lope de

1925 Poesías líricas I. Madrid, Ediciones La Lectura. Edición de José F. Montesinos.

2005 Rimas humanas y divinas del licenciado Tomé de Burguillos. Madrid, Castalia. Edición de Juan Manuel Rozas López y Jesús Cañas Murillo.

Zizi, Daniela (y Miguel López Coira)

2013 Poesía e improvisación. Modas y sonettos de Bernardo Zizi a los emigrantes sardos (un estudio metodológico). Granada, Comares, 2017.

2020 Hijos de las musas. La gara poética y otras formas de la poesía oral de improvisación. Madrid, 
CSIC.

Zorrilla, José

2017 Poesías. Madrid, Cátedra. Edición de Bienvenido Morros.

Zumthor, Paul

1991 Introducción a la poesía oral. Madrid, Taurus.

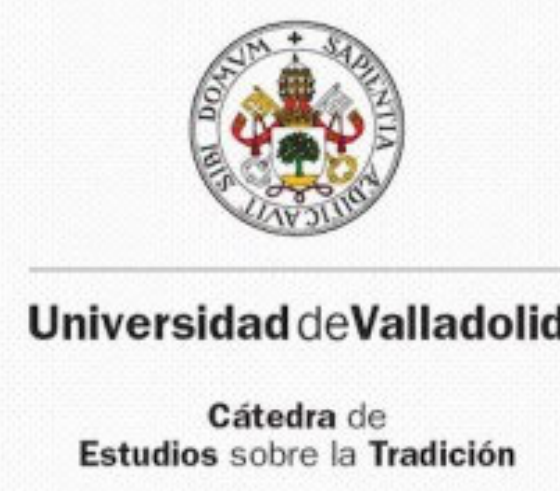

La Cátedra de Estudios sobre la Tradición

ha patrocinado este monográfico 